\title{
Seasonal changes in bovine fertility: relation to developmental competence of oocytes, membrane properties and fatty acid composition of follicles
}

\author{
Y. Zeron ${ }^{1}$, A. Ocheretny ${ }^{1}$, O. Kedar², A. Borochov ${ }^{3+}$, \\ D. Sklan ${ }^{2}$ and A. Arav ${ }^{1 *}$ \\ ${ }^{1}$ Institute of Animal Science, Agricultural Research Organization, The Volcani Center, Bet \\ Dagan, 50250, Israel; ${ }^{2}$ Department of Animal Science and ${ }^{3}$ The Kennedy-Leigh Centre for \\ Horticulture Research, Faculty of Agriculture, Food and Environmental Sciences, The \\ Hebrew University of Jerusalem, Rehovot 76100, Israel
}

Follicle dynamics and oocyte viability in Holstein primiparous and multiparous cows and the relationships between fertility and the biochemical and physical properties of oocyte membranes with season were examined. The conception rates of primiparous $(n=70885)$ and multiparous ( $n=143490$ ) cows differed, peaking in the winter and decreasing in the summer. The number of follicles $3-8 \mathrm{~mm}$ in diameter per ovary was higher in winter (19.6) compared with summer (12.0). However, in winter the percentage of ovaries with fewer than ten follicles per ovary was $16 \%$, in contrast to $50 \%$ in summer. After aspiration of follicles, 7.5 oocytes per ovary were found in winter and 5.0 oocytes per ovary in summer. Cleavage to the two- to four-cell stage after chemical activation was greater in winter than in summer; this was enhanced at the morula stage and embryo development to the blastocyst stage was significantly higher in winter than in summer. Determination of the lipid phase transition in oocyte membranes revealed a shift of $6^{\circ} \mathrm{C}$ between summer and winter. Fatty acid composition of phospholipids from follicular fluid, granulosa cells and oocytes indicated that there was a higher percentage of saturated fatty acids during the summer and that the percentages of mono-unsaturated and polyunsaturated fatty acids were higher in oocytes and granulosa cells during the winter. Oocytes and granulosa cells had similar fatty acid compositions, in contrast to follicular fluid. These results may explain the differences in the ability of oocytes to develop to the blastocyst stage at different seasons. Thus, temperature changes may lead to changes in membrane properties, which, in turn, can influence oocyte function and fertility.

\section{Introduction}

Seasonal changes in reproductive performance of cows are known to occur. These changes have been attributed to variation in temperature, humidity, photoperiod and nutrition (Thatcher, 1973; Tucker, 1982). Several reports have shown that fertility of dairy cows is negatively related to exposure of the female to high ambient temperature and humidity (Stott and Williams, 1962; Ingraham, 1974). Ron et al. (1984) reported that fertility in Israeli Holstein cattle followed a seasonal pattern, peaking in the winter (December-February) and decreasing in the summer (July-September). The authors explained these findings as attributable to the effects of high environmental temperatures on the endocrine system (Rosenberg et al., 1982), the ovaries and uterus (Wolfenson et al., 1995), and the embryo (Putney et al., 1989).

\footnotetext{
${ }^{\dagger}$ Deceased

*Correspondence

Email: arav@agri.huji.ac.il
}

High ambient temperatures affect the duration and intensity of expression of oestrus and, in addition, increase the duration of anoestrus and silent ovulation (Gwazdauskas et al., 1981). Bovine oestrous cycles are characterized by 2-3 waves of follicular development (Roche, 1996). Follicular dynamics in the ovary and corpus luteum change under conditions of heat stress (Wolfenson et al., 1995). Several reports have shown that there is a decrease in the number of small (3-5 $\mathrm{mm}$ in diameter) and medium (6-9 $\mathrm{mm}$ in diameter) follicles after exposure to heat stress (Wolfenson et al., 1995; Wilson et al., 1998). In contrast, Badinga et al. (1993) found that exposure of cows to high ambient temperature had no detectable effects on the overall pattern of growth of the first wave of follicular development but may alter the efficiency of ovarian follicular selection and dominance in later waves of follicle development.

Embryonic loss associated with maternal heat stress is a major cause of decreased fertility (Stott and Williams, 1962; Putney et al., 1989). Oocytes subjected to heat stress during meiotic maturation and ovulation had increased numbers of abnormal forms in mice (Baumgartner and 
Chrisman, 1981) and cows (Putney et al., 1989). Rocha et al. (1998) reported that the quality and developmental capabilities of bovine (Bos taurus) oocytes after in vitro fertilization decreased during the hot season (August versus May-June). In Holstein cows there was a decrease in the viability of in vitro (Ryan et al., 1992) and in vivo (Ryan et al., 1993) embryos from day 7 to day 14 in the hot season but not during the cold season.

A possible explanation for the effect of ambient temperature on embryonic development is modifications of the physical and chemical properties of the biomembranes. Temperature modulates the physical properties of the lipids in biological membranes, together with changes in the lipid composition of the membrane (Quinn, 1985). Accordingly, ambient temperatures regulate transitions from the liquid crystalline to the gel phase (termed lipid phase transition; Crowe et al., 1989). In addition, unsaturation of the acyl chains of membrane phospholipids increases during cold acclimation (Cossins and Raynard, 1987), which presumably depresses the midpoint ( $\mathrm{Tm}$ ) of the lipid phase transition. Injury to oocytes occurred close to the lipid phase transition (Arav et al., 1996) and was maximal at a Tm of $16^{\circ} \mathrm{C}$ (Zeron et al., 1999). This finding led to the hypothesis that changes in temperature might be the primary signal for regulation of fatty acid composition of membranes, which can affect membrane functionality and oocyte viability.

The aims of the present study were to examine the effect of season on follicle dynamics and oocyte viability, and the possible relationship with biochemical and physical properties of their membranes.

\section{Materials and Methods}

\section{Chemicals}

Unless otherwise stated, all chemicals were from Sigma Chemical Co (St Louis, MO).

\section{Temperature humidity index and conception rate in Israel}

During 1999 monthly temperature and humidity data were obtained from the Israeli National Meteorological Centre, which were calculated into the temperature humidity index (THI) as follows:

$\mathrm{THI}=\mathrm{DBT}-(0.55-0.55 \times$ relative humidity $) \times(\mathrm{DBT}-58)$

where DBT = dry bulb temperature $(F)$.

Accumulated data of conception rates were obtained from the Israeli Herd Book database. Data for Holstein primiparous and multiparous cows were plotted. A total of 70885 primiparous and 143490 multiparous cows were palpated between day 45 and day 50 after insemination and conception rates were recorded.

\section{Collection of ovaries, classification and in vitro maturation of oocytes}

Ovaries were obtained from a local abattoir from primiparous and multiparous Holstein cows and were placed in an insulated vessel containing physiological saline $(0.9 \%(\mathrm{w} / \mathrm{v}) \mathrm{NaCl})$ with $1 \times 10^{6}$ iu penicillin $\mathrm{ml}^{-1}$ and $1 \times 10^{6}$ iu streptomycin $\mathrm{ml}^{-1}$ at $32-36^{\circ} \mathrm{C}$. The ovaries were transferred to the laboratory within 60-90 min after collection and washed with $0.9 \%(\mathrm{w} / \mathrm{v}) \mathrm{NaCl}$ at $30-33^{\circ} \mathrm{C}$. The ovaries were cut through the centre and located over centred illumination where all the follicles were visible (transillumination aspiration ovary (TAO), IMT, Merchavia). The number of follicles (3-8 $\mathrm{mm}$ in diameter) per ovary were counted and the ovaries were classified into the following categories: small $(<10$ follicles per ovary), medium (11-20 follicles per ovary) and large (21-35 follicles per ovary). Cumulus-oocyte complexes (COCs) were aspirated from the follicles using an $18 \mathrm{~g}$ needle on a $10 \mathrm{ml}$ syringe. COCs were counted and washed three times in Hepes-TALP. Oocytes with three or more layers of cumulus cells surrounding a homogeneous cytoplasm were transferred into $500 \mu \mathrm{l}$ maturation medium (Leibfried and First, 1979; 40-60 COCs per well, in a four-well culture multi-dish (Nunc, Roskilde)): TCM-199 supplemented with $25 \mathrm{mmol}$ Hepes $\mathrm{I}^{-1}$, supplemented with $10 \%(\mathrm{v} / \mathrm{v})$ heatinactivated fetal calf serum (FCS) (Bio-lab, Jerusalem), $0.2 \mathrm{mmol}$ sodium pyruvate $\mathrm{I}^{-1}, 5 \mu \mathrm{g}$ gentamicin $\mathrm{I}^{-1}, 10 \mu \mathrm{g}$ ovine $\mathrm{LH} \mathrm{ml}^{-1}$ (NIADDK-NIH-26, AFP5551B, Bethesda, MD), $1 \mu \mathrm{g}$ ovine FSH ml-1 (NIADDK-NIH-20, AFP7028D, Bethesda) and $1 \mu \mathrm{g}$ oestradiol $\mathrm{ml}^{-1}$. The COCs were then incubated for $24 \mathrm{~h}$ at $38.5^{\circ} \mathrm{C}$ in a humidified atmosphere of $5 \% \mathrm{CO}_{2}$ in air.

\section{Oocyte activation and development}

After maturation, the oocytes were examined for their ability to develop to the blastocyst stage after chemical activation and culture for 8-10 days (Loi et al., 1998). COCs were denuded from cumulus cells in the maturation wells and placed for $5 \mathrm{~min}$ in ionomycin medium: $10 \mathrm{ml} \mathrm{TCM}$ 199 supplemented with $25 \mathrm{mmol}$ Hepes $\mathrm{I}^{-1}, 10 \%(\mathrm{v} / \mathrm{v})$ heat-inactivated FCS, $0.2 \mathrm{mmol}$ sodium pyruvate $\mathrm{I}^{-1}, 5 \mu \mathrm{g}$ gentamicin $\mathrm{I}^{-1}$ and $5 \mu \mathrm{mol}$ ionomycin $\mathrm{I}^{-1}$. Oocytes were transferred to 6-dimethylaminopurine (6-DMAP) medium (10 ml TCM 199 supplemented with 2 mmol 6-DMAP ${ }^{-1}$ ) for $4.5 \mathrm{~h}$. The oocytes were washed three times in a cleavage medium (IVF Cleavage Medium, Cook, Sydney) and transferred in groups of ten into $50 \mu \mathrm{l}$ drops of cleavage medium under mineral oil. Embryos were developed in an incubator under conditions of $38.5^{\circ} \mathrm{C}, 5 \% \mathrm{CO}_{2}, 5 \% \mathrm{O}_{2}$ and $95 \%$ humidity. Cleaved embryos were counted on day 4 (activation day $=$ day 0 ) and transferred to $50 \mu \mathrm{l}$ drops of blastocyst medium (IVF Blastocyst Medium, Cook, Sydney) under mineral oil. The blastocysts were counted after 8-10 days.

\section{Measurements of membrane phase transitions}

Evaluation of membrane phase transitions was conducted with a Bruker-Equinox 55 Fourier transform infrared (FTIR) connected to a Bruker FTIR microscope A590 (Ettlingen, D-76275) equipped with a liquid nitrogen- 


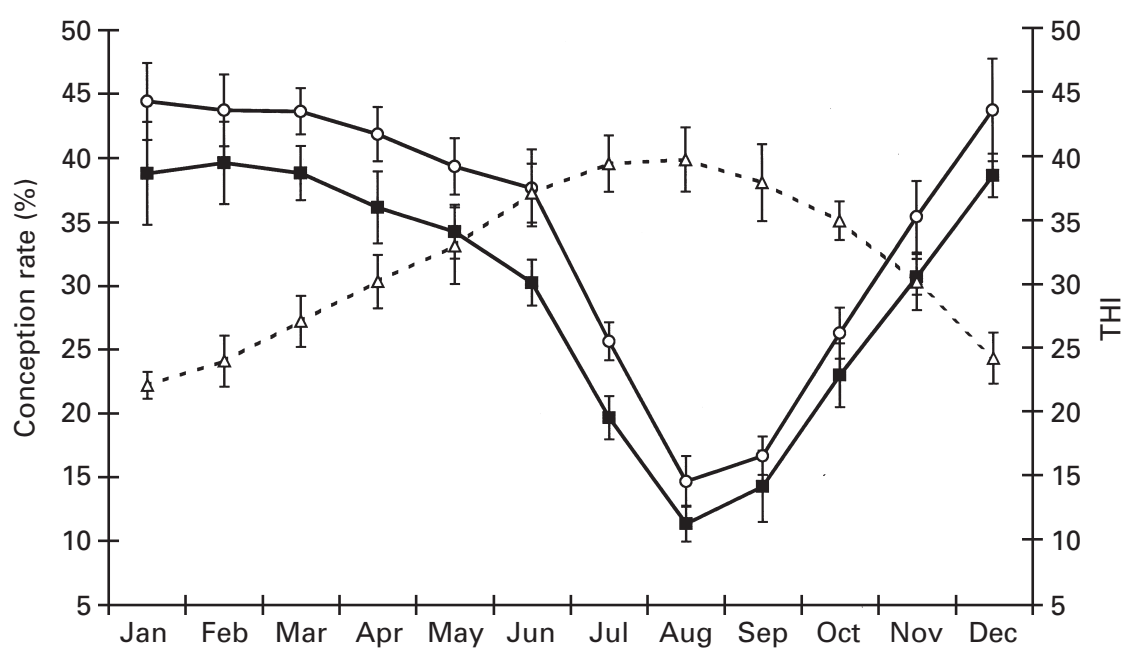

Fig. 1. The effects of season on the conception rate of primiparous $(\bigcirc)$ and multiparous cows, and the temperature humidity index (THI; $\triangle$ ). Monthly conception rate was determined in $5800 \pm 400$ (mean $\pm \mathrm{SE}$ ) and $11680 \pm 290$ primiparous and multiparous Cows, respectively. Values are mean $\pm \mathrm{SE}$.

cooled with mercury cadmium telluride (MCT) detector. The nominal spectral resolution used was $4 \mathrm{~cm}^{-1}$ and 66 scans were co-added per sample spectrum. Oocytes were placed in medium and sandwiched between two sapphire windows. Sample temperatures were regulated by a microprocessor feedback system, which measures temperature of a sample by a thermocouple on the face of the windows. The temperature was adjusted to within $0.1^{\circ} \mathrm{C}$ of the desired level and allowed to equilibrate for 2 min before the sample was scanned. The temperature was controlled by two thermoelectric coolers placed on the microscope using directional solidification cryo-stage (IMT). Data were processed to obtain FTIR spectra in the vibrational frequency of the methylene groups, most of which were in the hydrocarbon chain stretching region. The centre of the lipid phase transition curve, from liquid crystalline to gel phase, is designated $\mathrm{Tm}$. Tm values were calculated from the frequency-temperature plots by statistical analysis as described by Crowe et al. (1989).

\section{Evaluation of follicular fluid, granulosa cells and oocytes}

COCs were aspirated from the follicles and pooled together with the follicular fluid in a $50 \mathrm{ml}$ centrifuge tube (Corning, New York). The COCs and granulosa cells were aspirated into a $5 \mathrm{ml}$ pipette from the bottom of the centrifuge tube after centrifugation at $300 \mathrm{~g}$ for $10 \mathrm{~min}$. The follicular fluid was centrifuged at $1000 \mathrm{~g}$ for $10 \mathrm{~min}$ and $4 \mathrm{ml}$ of the upper fluid was aspirated, frozen at $-20^{\circ} \mathrm{C}$ and lyophilized. Oocytes were denuded from their cumulus cells by pipetting them into a $95 \mu$ l glass pipette. Denuded oocytes were vitrified in groups $(n=10)$ as described by Arav et al. (1993) and stored in liquid nitrogen. Granulosa cells were aspirated from the $100 \mathrm{~mm}$ Petri dish (Corning) that had contained the oocytes. These cells were washed three times by centrifugation at $500 \mathrm{~g}$ for $6 \mathrm{~min}$ with
Hepes-TALP, supplemented with $0.5 \%(\mathrm{w} / \mathrm{v})$ polyvinylpyrrolidone. A $200 \mu \mathrm{l}$ sample containing clean granulosa cells was aspirated, frozen at $-20^{\circ} \mathrm{C}$ and lyophilized.

\section{Fatty acid analyses}

Lyophilized samples of $100 \mu \mathrm{g}$ follicular fluid or granulosa cells (seven replicates in summer or winter) or 250 oocytes (six replicates in summer or winter) were extracted with $2 \mathrm{ml}$ chloroform-methanol (Folch et al., 1957). Lipid classes were separated by thin-layer chromatography on silica gel and fractions were identified by Comigration of authentic markers (Sklan et al., 1975). Absolute amounts of lipids were determined after addition of appropriate internal standards of heptadecanoyl phosphatidylcholine, triheptadecanoin or heptadecanoic acid by gas chromatography on a DEGS column as described by Sklan et al. (1975).

\section{Statistical analysis}

Mean values were calculated using the General Linear Model procedure of JMP (SAS Institute, 1994) and differences between treatments were examined by ANOVA. The level of significance was $P<0.05$ unless stated otherwise.

\section{Results}

The conception rates of all the cows were related to season (Fig. 1): the lowest conception rates were observed in August and September (11.3 and $14.2 \%$ for multiparous, and 14.6 and $16.6 \%$ for primiparous cows in August and September, respectively $)(P<0.05)$, whereas conception rates were higher in January and February (38.8 and 39.6\% 

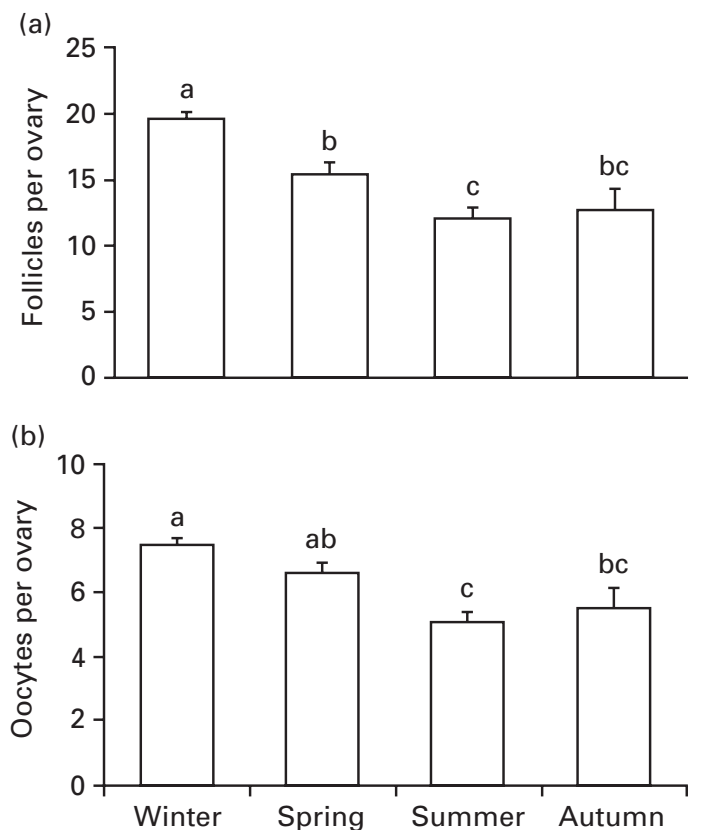

Fig. 2. Seasonal effects on the number of follicles and oocytes (intact and denuded) per ovary. (a) Follicles (3-8 $\mathrm{mm}$ in diameter) and (b) oocytes were aspirated from each ovary and counted. Data were pooled during winter (December-February: follicles: $n=19$ 980; oocytes: $n=7992$ ), spring (April-June: follicles: $n=12$ 180; oocytes: $n=4872$ ), summer (July-September: follicles: $n=10$ 360; oocytes: $n=4140$ ) and autumn (October-November: follicles: $n=2400$; oocytes: $n=960)$. Data are mean \pm SE. ${ }^{\text {abcBars }}$ with different letters are significantly different $(P<0.05)$.

for multiparous, and 44.4 and $43.7 \%$ in primiparous cows in January and February, respectively) $(P<0.05)$. These presumably season-related differences in conception rates were probably a result of changes in the number of follicles, oocytes or in oocyte development. Accordingly, ovarian dynamics were examined in relation to season.

Overall, 44920 follicles (3-8 $\mathrm{mm}$ in diameter) were aspirated during 1999. The numbers of follicles per ovary were higher in winter (Fig. 2) (19.6 follicles per ovary in December-March) than in summer (12.0 follicles per ovary in July-September) $(P<0.01)$. Recovery rates (percentage of oocytes per overall follicles) were not affected by season and ranged from 36 to $42 \%$; thus, an average of 7.5 oocytes per ovary was obtained in winter and 5.0 oocytes per ovary in summer (Fig. 2) $(P<0.01)$.

The percentage of ovaries with fewer than ten follicles per ovary is shown (Fig. 3). In summer, about half of the ovaries contained fewer than ten follicles per ovary. In contrast, during the winter the percentage of ovaries containing fewer than ten oocytes per ovary was $16 \%$, and most of the ovaries contained $>11$ follicles $(P<0.01)$. The proportion of ovaries with low numbers of follicles increased between April and September and then decreased.

Embryo development to the blastocyst stage was

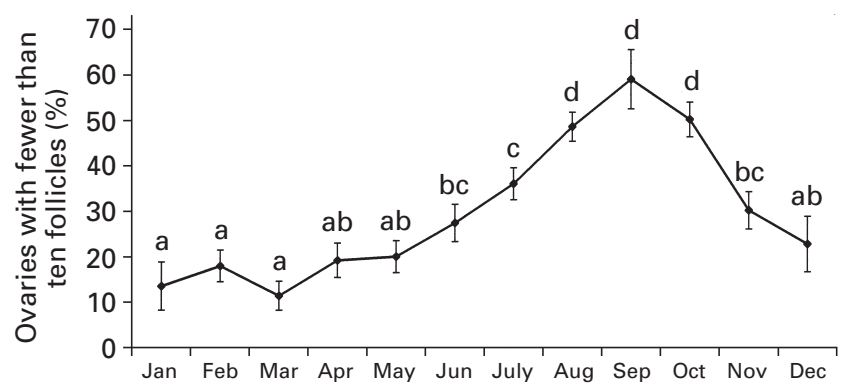

Fig. 3. Seasonal effects on the percentage of ovaries with fewer than ten follicles. The number of follicles $3-8 \mathrm{~mm}$ in diameter per ovary was counted at the same time as oocyte aspiration and data were pooled monthly. Data are mean $\pm \mathrm{SE}$. abcdValues with different letters are significantly different $(P<0.05)$.

significantly higher in winter than in summer (Fig. 4) $(P<0.05)$. Cleavage to the two- to four-cell stage was greater in winter than in summer, and this difference was enhanced at the morula stage. However, the ratio between the number of morulae found in winter and summer and the number of blastocysts found in winter and summer was not significantly different $(0.38$ and 0.30 , respectively). The morphology of winter and summer oocytes was different (Fig. 5). Homogeneous dark cytoplasm was visible in almost all the winter oocytes (approximately 85\%), in contrast to non-homogeneous dark regions in many summer oocytes (approximately 65\%). These differences led us to evaluate the biochemical and biophysical characteristics of the oocyte membrane.

Determination of the transition temperatures of lipids in the biological membranes from the liquid crystalline to the gel phase revealed a shift of $6^{\circ} \mathrm{C}$ between summer $(\mathrm{Tm}=$ $19.5^{\circ} \mathrm{C}$ ) and winter $\left(\mathrm{Tm}=13.5^{\circ} \mathrm{C}\right)$ (Fig. 6). Thus, the lipid profile in the membranes was examined.

The percentage and concentration of fatty acid composition of phospholipids (Tables 1 and 2, respectively) from oocytes, granulosa cells and follicular fluid were determined. A higher percentage of saturated fatty acids was found during the summer in oocytes $(16: 0, P<0.05)$, granulosa cells and follicular fluid (16:0 and 18:0, $P<0.05)$. In contrast, the percentages of polyunsaturated fatty acids (18:2-22:6) were significantly higher in oocytes and granulosa cells during the winter than in summer $(P<0.05)$. Oocytes and granulosa cells had a similar fatty acid composition, in contrast to follicular fluid, which showed different proportions of the fatty acids in the phospholipid fraction. However, arachidonic acid (20:4) comprised 1.1, 2.1 and $5.6 \%(\mathrm{w} / \mathrm{w})$ in the phospholipid fraction in oocytes, granulosa cells and follicular fluid, respectively in summer, whereas during winter it comprised $0.3,12.1$ and $9.1 \%(\mathrm{w} / \mathrm{w})$, respectively. Eicosapentaenoic acid (20:5, EPA) and docosapentaenoic acid (22:6, DHA) were not detected in oocytes and comprised $<1 \%(\mathrm{w} / \mathrm{w})$ in granulosa and follicular fluid in both seasons. 


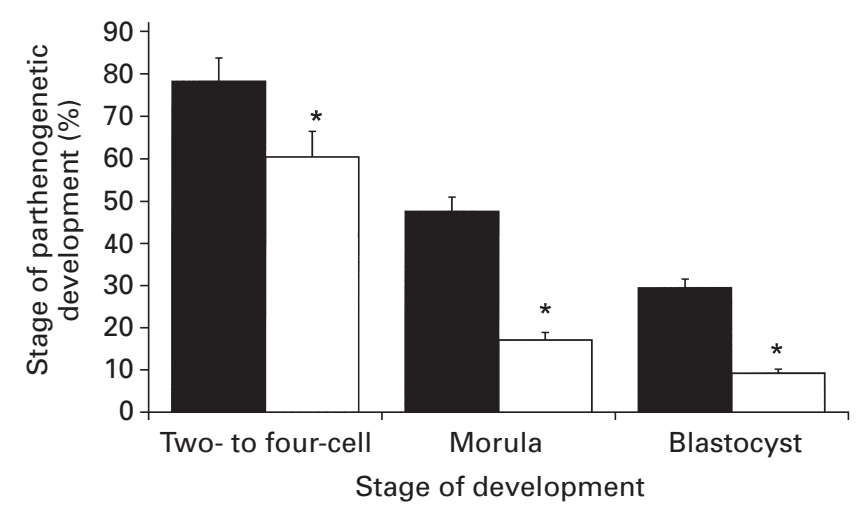

Fig. 4. Seasonal changes in embryonic development after chemical activation. Intact oocytes were aspirated from ovaries during the summer ( $\square$, July-September: $n=4140$ in 23 replicates) and winter ( $\mathbf{\square}$, December-February: $n=7992$ in 27 replicates) and matured, activated and cultured for 9 days. The stages of embryonic development were determined on days 2, 6 and 9 after activation (activation $=$ day 0 ). Values are mean \pm SE. ${ }^{*}$ Asterisks represent significant differences between seasons at each stage of development $(P<0.05)$.
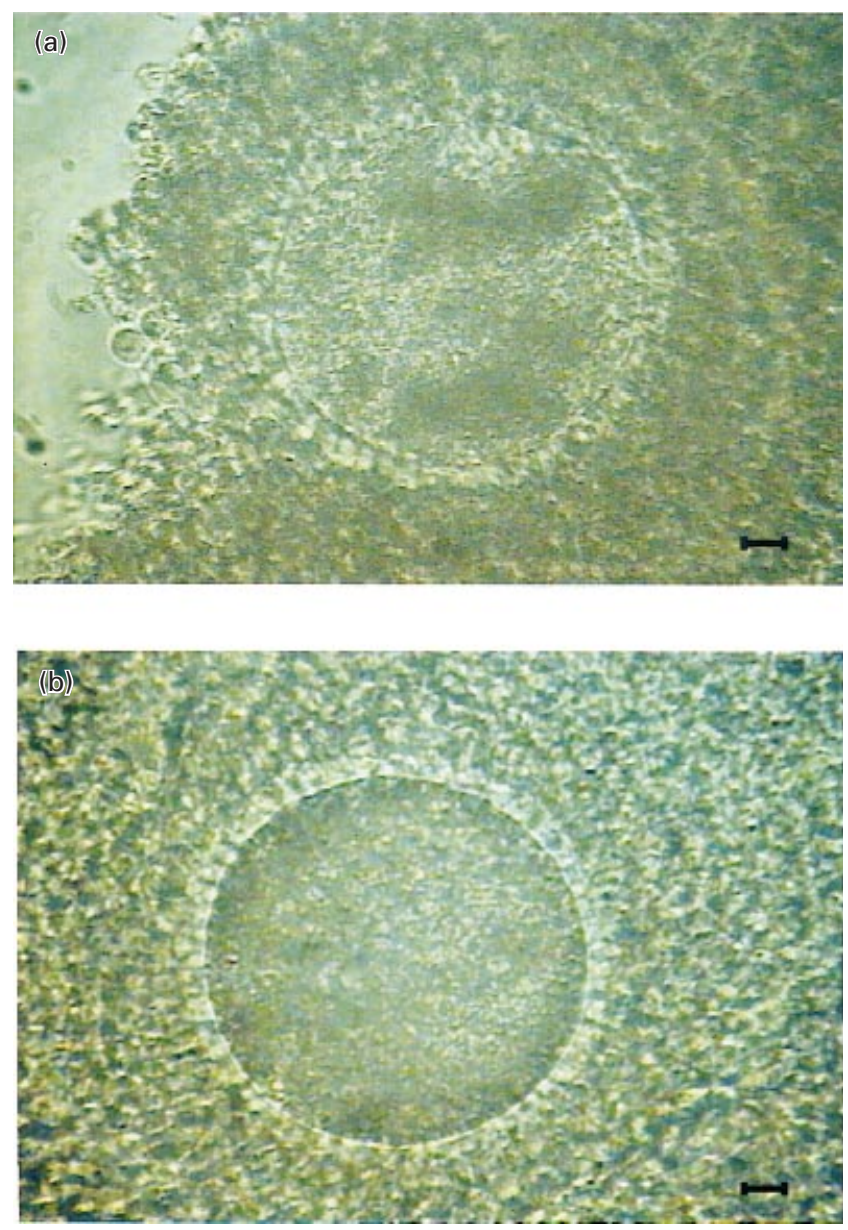

Fig. 5. Germinal vesicle stage in bovine oocytes. (a) Cumulus-oocyte complex (COC) with non-homogeneous dark regions that was more visible (approximately 65\%) during the summer and (b) COC with homogeneous dark cytoplasm that was more visible (approximately $85 \%$ ) during the winter. Scale bars represent $20 \mu \mathrm{m}$.

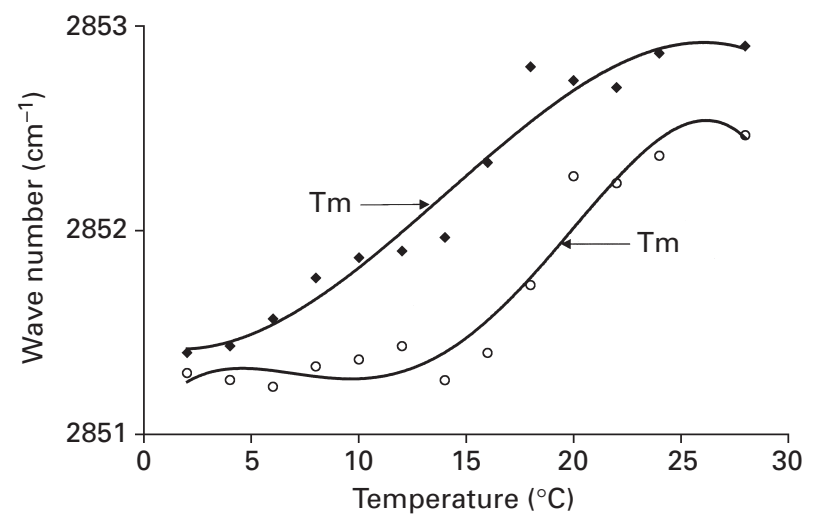

Fig. 6. Lipid phase transition of oocytes that were collected during the summer $(\bigcirc$; July-September) and the winter $\bullet$; DecemberFebruary). The phase properties of cytoplasmic membranes of oocytes in the germinal vesicle stage ( $n=15$ each season) were measured by Fourier transform infrared (FTIR) microscopy. The centre of the lipid phase transition curve, from liquid crystalline to gel phase, is designated Tm. Tm values were calculated from the frequency-temperature plots according to Crowe et al. (1989).

\section{Discussion}

Alterations in seasonal fertility are probably a result of multifactorial processes. A correlation between season and fertility was reported previously for cows in tropical and subtropical climates (Ingraham et al., 1974; Ron et al., 1984). The decrease in conception rate during the summer is a serious problem because of seasonal demands for milk and usually an increase in fertility is also required at this time. Although oocytes are the source of successful fertilization, only limited research has been carried out on oocyte parthenogenesis.

Follicular growth patterns are influenced by changes in body temperature. Studies of the effects of short term (7-14 days) heat stress showed that follicular dynamics are affected (Hahn, 1999): exposure to stress during the first follicular wave reduced the diameter and the volume of the dominant follicle and modified the hormonal profile (Badinga et al., 1993). In studies where heat stress was applied, oestradiol concentrations in the peripheral blood decreased between days 4-8 (Wolfenson et al., 1995) and days 11-21 of the cycle (Wilson et al., 1998). This finding might also explain the reduction in the number of follicles found in the ovary during the summer that was observed in the present study. The number of follicles per ovary was $>30 \%$ lower in the summer compared with winter. These differences were more pronounced when the percentage of ovaries that contained fewer than ten follicles per ovary was examined: most ovaries contained fewer than ten follicles during the summer, whereas in the winter most ovaries contained > 20 follicles. Wilson et al. (1998) reported similar findings using high temperatures, whereas the results of the present study reflect the entire period of high ambient temperatures. 


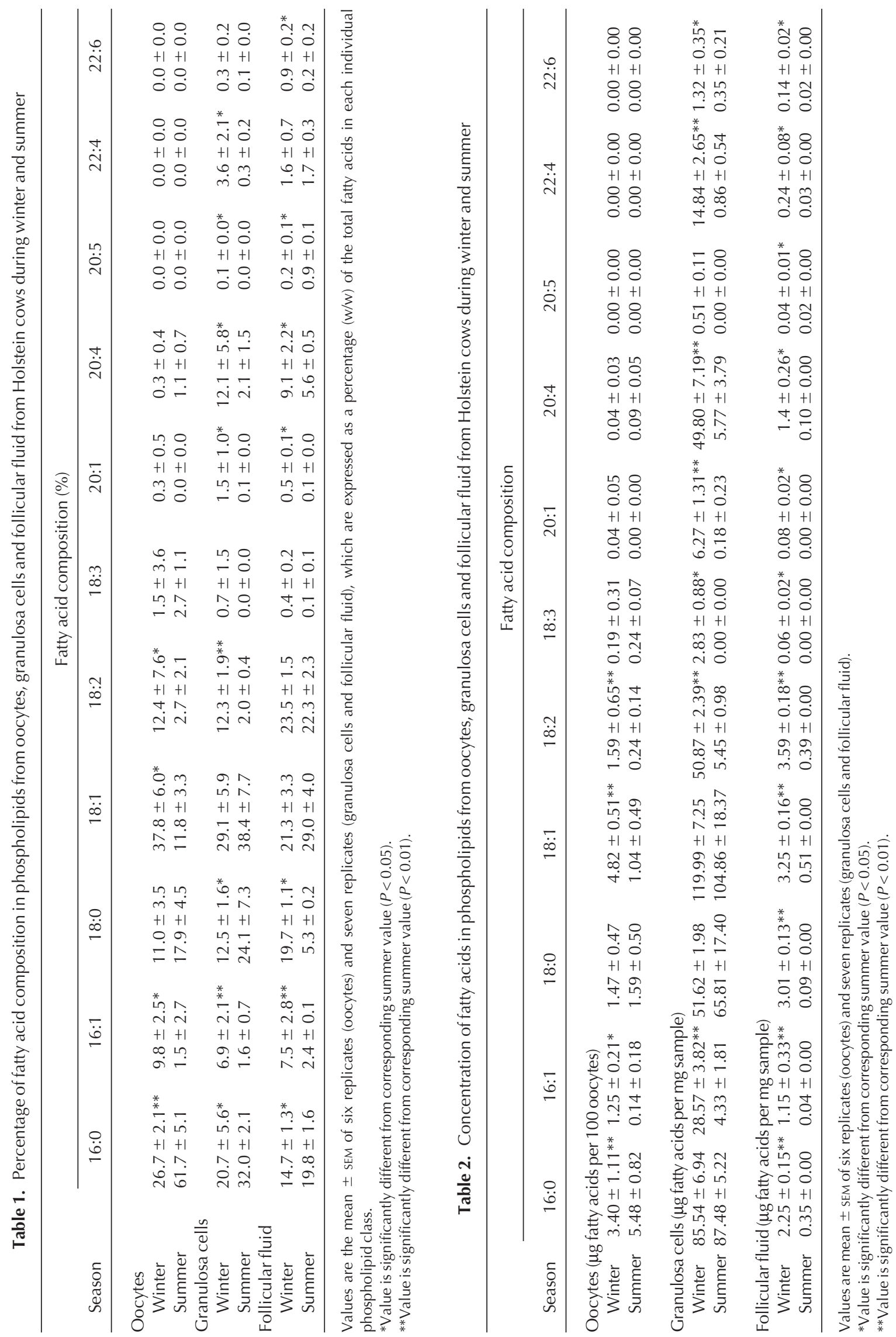


Seasonal effects on follicular dynamics have the potential to affect all the follicular cells (theca, granulosa, cumulus cells and oocytes) and significant differences were observed between winter and summer in the capacity for in vitro development of parthenogenic oocytes. This finding may be explained by the effects of heat stress in the summer. Putney et al. (1989) reported a similar finding after exposure of heifers to heat stress at the onset of oestrus. However, these authors observed no effects of heat stress on the rate of fertilization, although at later developmental stages (morulae and blastocysts), a decline in the proportion of normal embryos was found.

The shape and appearance of oocytes were modulated by season. Gross changes in the colour and homogeneity of the dark regions of the cytoplasm of oocytes were observed during the summer. One possibility is that lipid composition and content changed with season. Accordingly, some of their physical and compositional properties were examined.

It is known that environmental temperatures induce modifications in cellular components, including fatty acid unsaturation (Cossins and Raynard, 1987). The presence of a single double bond exerts a significant influence on the physical properties of membranes (Stubbs and Smith, 1984). An increase in the unsaturation of the fatty acids in biological membranes, associated with a higher membrane fluidity, is often a result of decreased temperature (Crowe et al., 1989). In the present study, examination of the physical and chemical characteristics of oocyte membranes revealed that their $\mathrm{Tm}$ value, at the germinal vesicle stage, decreased by $6^{\circ} \mathrm{C}$ between summer $\left(19.5^{\circ} \mathrm{C}\right)$ and winter $\left(13.5^{\circ} \mathrm{C}\right)$. Fatty acid profiles in the membrane phospholipids were then examined. Compositional differences were observed between membranes in winter and summer: in winter, the phospholipids of oocyte membranes had 2.2 times more polyunsaturated fatty acids compared with in summer. Nissen and Kreysel (1983) reported that polyunsaturated fatty acids are essential for gamete fertility. The polyunsaturated fatty acid content of ruminant phospholipids is influenced by hydrogenation of polyunsaturated fatty acids in the rumen, which results in lower concentrations of polyunsaturated fatty acids in membrane phospholipids (Sklan et al., 1971). The major fatty acid in the membrane phospholipids of bovine germinal vesicle oocytes during the winter was palmitic acid, followed by oleic acid. This composition is similar to reports on the composition of sheep and bovine immature oocytes (McEvoy et al., 2000). The major differences in the phospholipid profile of bovine germinal vesicle oocytes between winter and summer were in the palmitic, palmitoleic, oleic, linoleic and linolenic acids. These changes in fatty acid content in oocyte membranes may explain, in part, the shift in $\mathrm{Tm}$ between winter and summer. Changes in transition temperatures are also related to fatty acid chain length and, particularly, to the positions of the double bond (Stubbs and Smith, 1984). Higher concentrations of oleic acid in the membrane phospholipid profile during the winter may play a role in the changes in the lipid phase transition temperature. In addition, linoleic acid plays a major role in mammalian oocyte growth and differentiation (Nishizuka, 1988), and stimulates the activity of adenylate cyclase (Racowsky, 1985) and protein kinase C (Dell and Severson, 1989). Linoleic acid can also serve as precursor for prostaglandins and leukotrienes, which have potent effects as local hormones (Smith, 1989). In addition, in the present study, the follicular fluid contained 9.1 and $5.6 \%(\mathrm{w} / \mathrm{w})$ arachidonic acid in winter and summer, respectively. The same trend was observed in granulosa cells, in which arachidonic acid comprised 12.1 and 2.1\% $(\mathrm{w} / \mathrm{w})$ during winter and summer, respectively. In contrast, oocytes contained $<1 \%(\mathrm{w} / \mathrm{w})$ arachidonic acid during all seasons. This finding may be important, as arachidonic acid is a major precursor of prostaglandins. However, EPA and DHA were not present in the profiles of bovine oocytes, which is a similar finding to other reports in both ovine and pig oocytes (Homa et al., 1986; Coull et al., 1998; McEvoy et al., 2000). Interestingly, these two fatty acids were present at high concentrations (>30\%) in bovine sperm membranes and play a major role in fluidity (Parks and Lynch, 1992).

The lipid profile in granulosa cells was very similar to that of the oocytes. It should be noted that the fatty acids profile in follicular fluid phospholipid showed smaller differences between seasons compared with the changes observed in the phospholipid of granulosa cells and oocytes.

Together, these results may explain the influence of temperature on the ability of oocytes to develop to the blastocyst stage at different temperatures. Temperature changes lead to alterations in the biochemical properties of the membranes and this, in turn, may influence oocyte functionality and fertility.

This research was supported in part by a grant from the US-Israel Binational Agricultural Research and Development Fund (BARD2528-96) and the Hasherut A. I. Center. The authors would like to thank ICBA for valuable information from the Israel herd book. The authors thank NHPP for generous provision of FSH and LH. This article is a contribution from the Agricultural Research Organization, The Volcani Center, Bet Dagan, Israel No. 355/00 series.

\section{References}

Arav A, Shehu D and Mattioli M (1993) Osmotic and cytotoxic study of vitrification of immature bovine oocytes Journal of Reproduction and Fertility 99 353-358

Arav A, Zeron Y, Leslie SB, Behboodi E, Anderson GB and Crowe JH (1996) Phase transition temperature and chilling sensitivity of bovine oocytes Cryobiology 33 589-599

Badinga L, Thatcher WW, Diaz T, Drost M and Wolfenson D (1993) Effect of environmental heat stress on follicular development and steroidogenesis in lactating Holstein cows Theriogenology 39 797-810

Baumgartner AP and Chrisman CL (1981) Ovum morphology after hyperthermic stress during meiotic maturation and ovulation in the mouse Journal of Reproduction and Fertility 61 91-96

Cossins AR and Raynard RS (1987) Adaptive responses of animal cell membranes to temperature. In Temperature and Animal Cells pp 95-112 Eds K Bowler and BJ Fuller. The Society for Experimental Biology by The Company of Biologists Limited, Cambridge 
Coull GD, Speake BK, Staines ME, Broadbent PJ and McEvoy TG (1998) Lipid and fatty acid composition of zona-intact sheep oocytes Theriogenology 49179

Crowe JH, Hoekstra FA, Crowe LM, Anchordoguy TJ and Drobnis E (1989) Lipid phase transitions measured in intact cells with Fourier transform infrared spectroscopy Cryobiology 26 76-84

Dell KR and Severson DL (1989) Effect of cis-unsaturated fatty acids on aortic protein kinase C activity Biochemistry Journal 258 171-175

Folch J, Lees M and Sloane-Stanley GH (1957) A simple method for the isolation and purification of total lipids from animal tissue Journal of Biological Chemistry 226 497-509

Gwazdauskas FC, Thatcher WW, Kiddy CA, Paape MJ and Wilcox CJ (1981) Hormonal patterns during heat stress following PGF $_{2 \alpha}$-tham salt induced luteal regression in heifers Theriogenology 16 271-285

Hahn GL (1999) Dynamic responses of cattle to thermal heat loads Journal of Animal Science 77 (Supplement 2/J) 10-20

Homa ST, Racowsky C and McGaughey RW (1986) Lipid analysis of immature pig oocytes Journal of Reproduction and Fertility $\mathbf{7 7}$ 425-434

Ingraham RH, Gillette DD and Wagner WD (1974) Relationship of temperature and humidity to conception rate of Holstein cows in subtropical climates Journal of Dairy Science 57 476-481

Leibfried L and First NL (1979) Characterization of bovine follicular oocytes and their ability to mature in vitro. Journal of Animal Science 53 76-86

Loi P, Ledda S, Fulka J, Jr, Cappa P and Moor RM (1998) Development of parthenogenetic and cloned ovine embryos: effect of activation protocols Biology of Reproduction 58 1177-1187

McEvoy TG, Coull GD, Broadbent PJ, Hutchinson JSM and Speake BK (2000) Fatty acid composition of lipids in immature cattle, pig and sheep oocytes with intact zona pellucida Journal of Reproduction and Fertility $118163-170$

Nishizuka Y (1988) The molecular heterogeneity of protein kinase C and its implications for cellular regulation Nature (London) 334 661-665

Nissen HP and Kreysel HW (1983) Polyunsaturated fatty acids in relation to sperm motility Andrologia 15 264-269

Parks JE and Lynch DV (1992) Lipid composition and thermotropic phase behavior of boar, bull, stallion, and rooster sperm membranes Cryobiology 29 255-266

Putney DJ, Mullins S, Thatcher WW, Drost M and Gross TS (1989) Embryonic development in superovulated dairy cattle exposed to elevated ambient temperatures between the onset of estrus and insemination Animal Reproduction Science 19 37-51

Quinn PJ (1985) A lipid-phase separation model of low-temperature damage to biological membranes Cryobiology 22 128-146

Racowsky C (1985) Effect of forskolin on maintenance of meiotic arrest and stimulation of cumulus expansion, progesterone and cyclic AMP production by pig oocyte-cumulus complexes Journal of Reproduction and Fertility 74 9-21

Rocha A, Randel RD, Broussard JR, Lim JM, Blair RM, Roussel JD, Godke RA and Hansel W (1998) High environmental temperature and humidity decrease oocyte quality in Bos taurus but not in Bos indicus cows Theriogenology 49 657-665

Roche JF (1996) Control and regulation of folliculogenesis - a symposium in perspective Reviews of Reproduction 1 19-27

Ron M, Bar-Anan R and Wiggans GR (1984) Factors affecting conception rate of Israeli Holstein cattle Journal of Dairy Science 67 854-860

Rosenberg M, Folman Y, Herz Z, Flamenbaum I, Berman A and Kaim M (1982) Effect of climatic conditions on peripheral concentrations of $\mathrm{LH}$ progesterone and oestradiol-17 $\beta$ in high milk-yielding cows Journal of Reproduction and Fertility 66 139-154

Ryan DP, Blakewood EG, Lynn JW, Munyakazi L and Godke RA (1992) Effect of heat-stress on bovine embryo development in vitro. Journal of Animal Science 70 3490-3497

Ryan DP, Prichard JF, Kopel E and Godke RA (1993) Comparing early embryo mortality in dairy cows during hot and cool seasons of the year Theriogenology 39 719-737

SAS Institute (1994) JMP ${ }^{\circledR}$ User's guide. Version 3. SAS Institute Inc, Cary, $\mathrm{NC}$

Sklan D, Volcani R and Budowski P (1971) Formation of octadecadienoic acid by rumen liquor of calves, cows and sheep in vitro. Journal of Dairy Science 54 515-519

Sklan D, Hurwitz S, Budowski P and Ascarelli I (1975) Fat digestion and absorption in chicks fed raw or heated soybean meal Journal of Nutrition $10557-63$

Smith WL (1989) The eicosanoids and their biochemical mechanisms of action Biochemistry Journal 259 315-324

Stott GH and Williams RJ (1962) Causes of low breeding efficiency in dairy cattle associated with seasonal high temperatures Journal of Dairy Science 45 1369-1375

Stubbs CD and Smith AD (1984) The modification of mammalian membrane polyunsaturated fatty acid composition in relation to membrane fluidity and function Biochimica et Biophysica Acta 779 89-137

Thatcher WW (1973) Effects of season, climate, and temperature on reproduction and lactation Journal of Dairy Science 57 360-368

Tucker HA (1982) Seasonality in cattle Theriogenology 17 53-59

Wilson SJ, Marion RS, Spain JN, Spiers DE, Keisler DH and Lucy MC (1998) Effects of controlled heat stress on ovarian function of dairy cattle 1 Lactating cows Journal of Dairy Science 81 2124-2131

Wolfenson D, Thatcher WW, Badinga L, Savio JD, Meidan R, Lew BJ Braw-Tal R and Berman A (1995) Effect of heat stress on follicular development during the estrous cycle in lactating dairy cattle Biology of Reproduction 52 1106-1113

Zeron Y, Pearl M, Borochov A and Arav A (1999) Kinetic and tempora factors influence chilling injury to germinal vesicle and mature bovine oocytes Cryobiology 38 35-42

Received 25 May 2000.

Accepted 9 October 2000. 